\title{
EFFECT OF NET CROSS-SHORE SAND TRANSPORT ON BEACH PROFILES
}

\author{
Sravani Mallavarapu, University of Delaware, sravani@udel.edu \\ Nobuhisa Kobayashi, University of Delaware, nk@udel.edu \\ Tingting Zhu, University of Delaware, ztting@udel.edu
}

\section{EQUILIBRIUM BEACH PROFILES}

The concept of an equilibrium beach profile is convenient and widely adopted for long-term simulations of shoreline changes and beach profile evolutions. The equilibrium profile is regarded as a profile with net cross-shore sediment transport rate $\mathrm{q}_{\mathrm{n}}=0$. Kobayashi et al. (2008) proposed formulas for offshore suspended sediment transport rate $q_{s}$ and onshore bedload transport rate $q_{b}$ and derived the equilibrium profile equation of Dean (1991) for the case of $q_{n}=\left(q_{s}+q_{b}\right)=0$. Their model is extended to equilibrium profiles with net offshore $\left(q_{n}<0\right)$ and onshore $\left(q_{n}>0\right)$ sediment transport rates. The equilibrium profile with $\mathrm{q}_{\mathrm{n}}=0$ is modified by periodic beach nourishment $\left(\mathrm{q}_{\mathrm{n}}<0\right)$ and frequent sediment overwash $\left(q_{n}>0\right)$. The extended model predicts the degree and location of profile modifications as a function of $q_{n}$ and it can be used to improve beach nourishment design and devise barrier beach overwash countermeasures.

\section{EXPERIMENT}

An equilibrium profile of an actual beach is difficult to pinpoint because of the time-varying water level and waves. An experiment was conducted in a wave flume that is $30 \mathrm{~m}$ long, $1.15 \mathrm{~m}$ wide and $1.5 \mathrm{~m}$ high. The sand beach in the flume consists of well sorted fine sand with a median diameter of $0.18 \mathrm{~mm}$. A 400 -s run of irregular waves with a TMA spectrum was generated by a pistontype wave maker in a water depth of $88 \mathrm{~cm}$. The spectral significant wave height and peak period were approximately $17 \mathrm{~cm}$ and $2.6 \mathrm{~s}$. Eight wave gauges were used to measure the free surface elevation from outside the surf zone to the swash zone. The fluid velocities in the surf zone were measured by three velocimeters. The beach profiles were measured using a laser line scanner system.

Three tests were performed to produce equilibrium profiles for zero, negative and positive values of $q_{n}$ (Figure 1). The measured profile was assumed to be in equilibrium when the profile change under ten runs (4000s) was close to measurement errors of a few millimeters. The first test with zero $(Z)$ net rate was conducted to establish an equilibrium profile with a step near the lower limit of wave downwash for the given sediment and waves. The second test with negative $(N)$ net rate was initiated on the equilibrium profile of test $Z$ with sand placed at the still water shoreline. The placed sand mass corresponded to the net rate of $q_{n}=-0.006 \mathrm{~cm}^{3} / \mathrm{s} / \mathrm{cm}\left(19 \mathrm{~m}^{3} / \mathrm{yr} / \mathrm{m}\right)$. The placed sand was dispersed quickly in the swash zone. An equilibrium profile was established after 20 runs where foreshore slope shifted $0.1 \mathrm{~m}$ seaward. The third test with positive $(P)$ net rate was started from the final profile of test $N$. The still water level was increased by $4 \mathrm{~cm}$ to initiate wave overtopping and overwash over the vertical wall located at the onshore coordinate $x=19.9 m$ where the incident waves were measured at $x=0$. The wave overtopping rate and sand overwash rate were measured by collecting overtopped water and sand in a collection basin during each 400-s run. The measured rates decreased somewhat as the sand was deposited on the upper foreshore slope. The final profile after 20 runs was in quasi-equilibrium. The step of test $\mathrm{N}$ shifted $0.2 \mathrm{~m}$ landward. The sand overwash rate for the last ten runs was $q_{n}=0.003 \mathrm{~cm}^{3} / \mathrm{s} / \mathrm{cm}$. The differences among the three profiles shown in Figure 1 were discernible in the inner surf and swash zones but found to be relatively small.

\section{ANALYTICAL AND NUMERICAL MODELING}

The above data are used to adjust the model for arbitrary net rate $q_{n}$. The adjusted model is used to evaluate the effects of $q_{n}$ on laboratory and prototype beaches for much wider ranges of $q_{n}$. The cross-shore numerical model CSHORE (Kobayashi 2016) is compared with the experimental data to assess its capability for predicting small erosional and accretional profile changes of quasiequilibrium profiles. The offshore beach profile responded a little to the continuous sand placement at the shoreline and sand overwash above the shoreline.

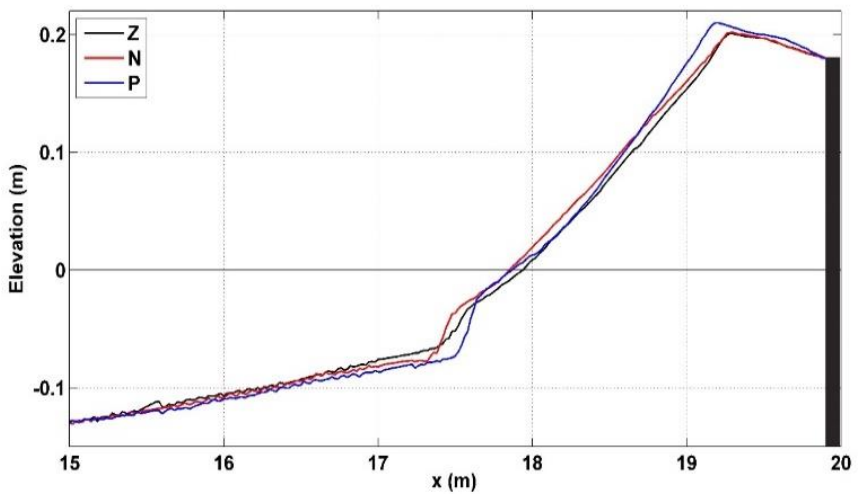

Figure 1 Final profiles of zero $(\mathrm{Z})$, negative $(\mathrm{N})$ and positive $(P)$ net cross-shore sediment transport tests.

\section{REFERENCES}

Dean R.G (1991). "Equilibrium beach profiles: characteristics and applications." J.Coastal Research, 7, 53-84.

Kobayashi, N. (2016). "Coastal sediment transport modeling for engineering applications." J. Waterway, Port, Coastal, and Ocean Engineering, 142(6), 1-23.

Kobayashi N, Payo.A, and Schmied.L. (2008) "Cross-shore suspended sand and bed load transport on beaches." J.Geophysical Research, 113, C07001, 1-17. 